${ }^{\circ}$ Entomologica Fennica. 3 November 1997

\title{
Chironomus esai n. sp. (Diptera: Chironomidae) in lakes and reservoirs of central Fennoscandia
}

\author{
Wolfgang F. Wülker
}

\begin{abstract}
Wülker, W. F. 1997: Chironomus esai n. sp. (Diptera: Chironomidae) in lakes and reservoirs of central Fennoscandia. - Entomol. Fennica 8: 171-176.

The paper describes karyotype and larval, pupal and adult morphology of Chironomus esai n. sp., which is an important component in Fennoscandian reservoir lakes.

Wolfgang F. Wülker, Biol. Inst. I (Zoology) of the university, Hauptstr. 1, D-79104 Freiburg, Germany
\end{abstract}

Received 9 April 1996, accepted 12 August 1996

\section{Introduction}

Species of the genus Chironomus are very common in Fennoscandian lakes but, despite this fact, are not that well known.

In May 1980, I visited lake Lilla Galtsjön, $24 \mathrm{~km}$ NE of Karshamn (South Sweden), in collaboration with K. Bureke, Limnological Institute, and L. Säwedal, Zoological Institute University of Lund. The deeper part of the lake was to be calcified and the effect this treatment had on the benthal chironomids (Lindmark 1982) investigated. We found that even before the treatment, the species were different in the deeper $(6 \mathrm{~m})$ and the more shallow parts $(1-3 \mathrm{~m})$, the former being inhabited by Chironomus anthracinus, the latter by larvae with an unknown karyotype.

In June 1985, during a stay at the Water District Laboratory in Vaasa (Central Finland), I found together with Esa Koskenniemi the same new karyotype in the reservoirs Hirvijärvi and Liikapuro. Lauri Paasivirta contributed some larvae from Vatianjärvi, near Jyväskylä, central Finland.

In 1988, Esa Koskenniemi was successful in rearing some of the typical semireductus-type larvae to the adult state ( 2 males, 2 females).
Langton (1991) included pupal skins of our material (as species Pe 13) in his updated key for pupal exuviae, the pupa of C. esai was found to have a very uncommon appearance of the anal spur.

I will describe here the karyotype and morphology of the new species, which no doubt is an important component in the benthos of reservoir lakes in central Fennoscandia.

\section{Material and methods}

Sweden : Lilla Galtsjön $20 \mathrm{~km}$ NE of Karshamn, South Sweden, 3 chromosome squashes, 29.II.1980, K. Bjureke; 8 chrom. sq. with larval heads, 1-2-m depth in front of bathing place, 7.V.1980, W. Wülker, L. Säwedal, K. Bjureke.

Finland: Hirvijärvi, $62^{\circ} 49^{\prime} \mathrm{N} 23^{\circ} 08^{\prime} \mathrm{E}$, Seinäjoki area in western Finland (near Vaasa), 1 chrom. sq., 20.V.1985, from 4-m depth, species parasitized by microsporideans, W. Wülker (WW), E. Koskenniemi (EK); 2 chrom. sq. with larval bodies, 2 male adults, 2 female adults with pupal skins, reared from the typical semireductus-type larvae, 27.VI.1988, EK; Liikapuro, $62^{\circ} 22^{\prime}$ N $23^{\circ} 06^{\prime} \mathrm{E}$, Seinäjoki area, 3-m depth in dead Sphagnum, 1 chrom. sq. with larval head, V.1985, WW, EK; Vatianjärvi, $62^{\circ} 30^{\prime} \mathrm{N} 25^{\circ} 50^{\prime} \mathrm{E}, 1$ chrom. sq., 20.V.1985, L. Paasivirta.

For characterization of the karyotype, I followed Keyl (1962) and Dévai et al. (1989); for the measurements of 

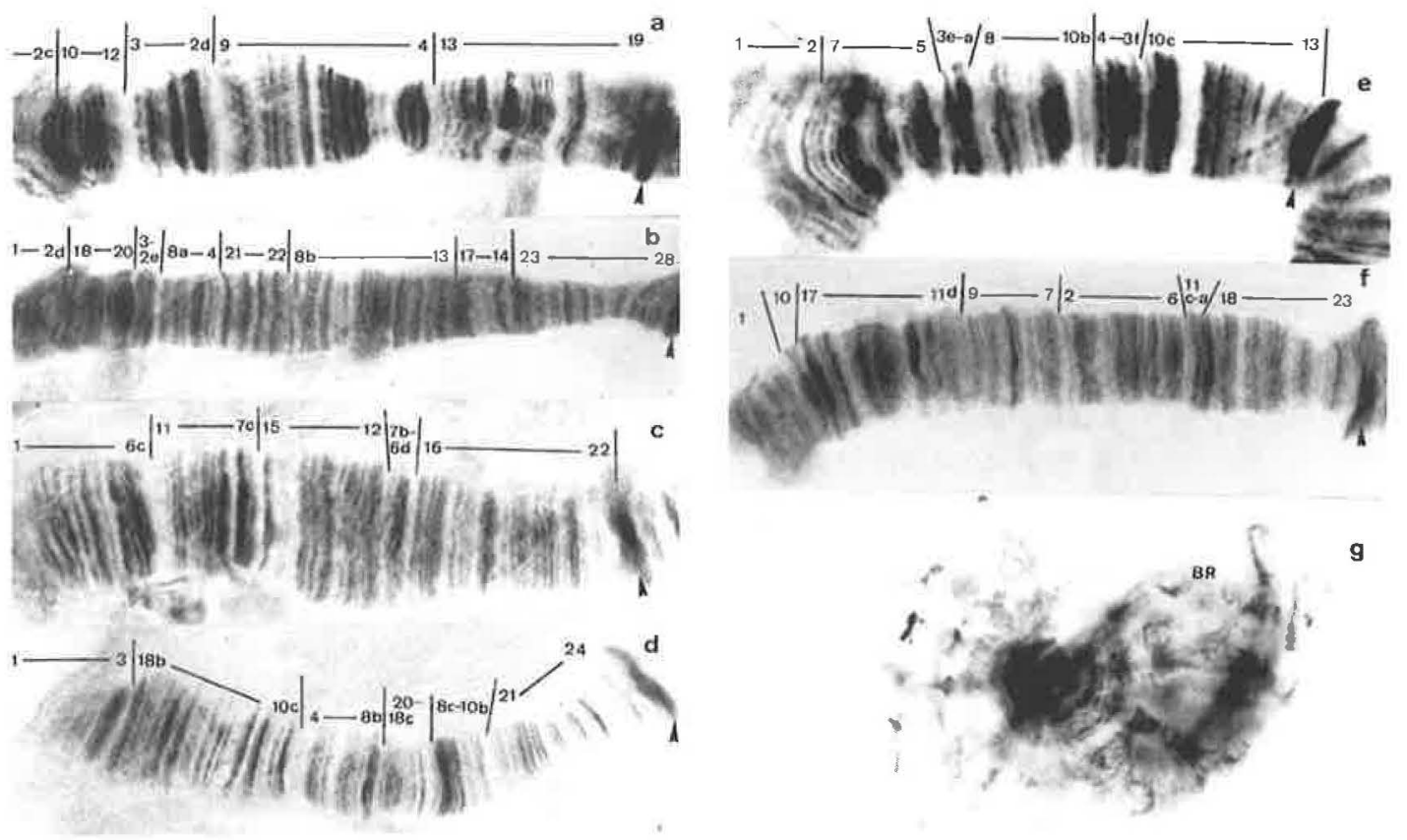

Fig. 1. Karyotype. - a: Chromosome arm A. — b: Arm B. - c: Arm C. - d: Arm D. - e: Arm E. - f: arm F. - g: Arm G. Arrow heads $=$ centromeres. $B R=$ Balbiani ring.

larvae, Webb and Scholl (1985); for terminology of larval, pupal and adult characters, Saether (1980). The preparation of specimen was routine (chromosome squashes Keyl \& Keyl 1959, adults Schlee 1966).

\section{Results and discussion}

Chironomus esai nov. spec.

Preliminary names: Sk16 (Langton 1991, Koskenniemi 1994, 1995), spec. a (Koskenniemi 1992).

Holotype: chromosome squash V18, Hirvijärvi/Finland 1985, leg. W. Wülker, Zoologische Staatssammlungen München.

Paratypes: 1 male, 1 female adult, both with pupal skin, reared by E. Koskenniemi, Hirvijärvi, 1988, Zoologische Staatssammlungen München; chromosome squash V30, Liikapuro, and reared adults from Hirvijärvi in coll. Wülker Freiburg.

I dedicate this species to my friend Esa Koskenniemi, who was a pioneer in the investigation of reservoir lakes in central Finland and clarified the species by rearing pupae and adults from larvae.

\section{Description}

\subsection{Karyotype}

$2 \mathrm{n}=8$. Chromosome arm combination $\mathrm{AB}, \mathrm{CD}$, $\mathrm{EF}, \mathrm{G}$ (thummi-complex). Centromeres heterochromatinized, nucleolus in arm C, inversion polymorphism not present in the available 15 chromosome preparations.

Arm A (Fig. 1a): 1-2c 10-12 3-2d 9-4 13-19. Identical with $C$. holomelas and many other species (basic pattern sensu Wülker 1980).

Arm B (Fig. 1b): 1-2d 18-20 3-2e 8a-4 21-22 8b-13 17-14 23-28. Possibly identical with C. major (Wülker \& Butler 1983) and C. tenuistylus (Wülker 1991a). The proximal piece 8b-13 17-14 23-28 is frequent in primitive species of the genus.

Arm C (Fig. 1c): 1-6c 11-7c 15-12 7b-6d 16-22. Pattern common in primitive species: $C$. anthracinus, aberratus, fraternus, beljaninae, jonmartini, tardus, neocorax, riihimakiensis, staegeri, pilicornis and whitseli (see Wülker 1991b). 
Arm D (Fig. 1d): 1-3 18b-10c 4-8b 20-18c 8c$10 \mathrm{~b}$ 21-24.

Arm E (Fig. 1e): 1-2 7-5 3e-a 8-10b 4-3f $10 \mathrm{c}-13$. Possibly identical with $\mathrm{E}_{2}$ of $C$. fraternus and C. beljaninae (Wülker 1991b).

Arm F (Fig. 1f):

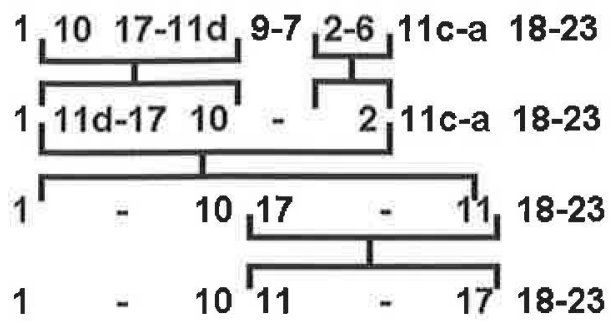

Can be derived from the standard pattern of C. piger by 4 inversions.

Arm G (Fig. 1g): Paired, short; a constriction divides the small fan shaped part at one end from a part with more clear bands and a Balbiani ring followed by a group of terminal bands at the other end.

\subsection{Larva}

Length ca. $18 \mathrm{~mm}$, semireductus-type, i.e. small lateral appendages of abdominal segment VII ( $1 / 8$ of segment length) and two pairs of small ventral tubules at segment VIII (1/4 segment length).

Head: hind part of gula dark, head stripe on clypeus present, but not very distinct.

Measurements on eight IV instar larvae, in $\mu \mathrm{m}$ : head width 700-750(725), clypeus size 290312 (298.8), fourth tooth of mandibula unpigmented, distance of first lateral teeth of mentum (MS) 59-75(67), antenna length first segment $\left(\mathrm{L}_{1}\right)=$ $160-184(170), L_{2}=38-45(40)$, width of first segment $\left(\mathrm{W}_{1}\right)=38-45(43)$, distance ring organ from base $(\mathrm{R})=53-82(74), \mathrm{L}_{\mathrm{l}} / \mathrm{W}_{\mathrm{j}}=4.0-5.1(4.32)$, $\mathrm{L}_{1} / \mathrm{L}_{2}=4.0-5.1(4.49), \mathrm{L}_{2} / \mathrm{W}_{1}=0.83-1.09(0.99)$, $\mathrm{R} / \mathrm{W}_{1}=1.27-2.2(1.84)$. Epipharyngeal teeth 1316.

\subsection{Pupa}

With $15 \mathrm{~mm}$ exuvial length (Langton 1991), C. esai belongs to the large Chironomus species like $C$. plumosus, but is different from that species by presence of a very unique character: "Comb of segment VIII with 4-8 teeth unusual for Chironomus: the teeth narrow rapidly from base to a long thin point; these points hardly converge apically giving the appearance, although the bases of the points are contiguous, that they are separate from each other; the comb is set on a bulbous swelling which flattens out on a slide to give a square-ended appearance (plate $102 \mathrm{~m}$ )". Other characters mentioned in Langton (1991): Cephalic tubercles large, strongly curved. Thoracic horn basal ring $225 \times 90 \mu \mathrm{m}$, tracheal patch $175 \times 28 \mu \mathrm{m} ; 8$ tracheoles across, $3-3.5 \mu \mathrm{m}$ diameter. Hook row IIB 0.42 BbII; 107 hooks. Comb of segment VIII $4 / 8$ teeth. Lateral filamentous setae IX ca. 200. Thorax granulate anterior, indistinctly granulate medially, smooth posteriorly. Pleura IV without spinules.

\subsection{Adults}

\subsubsection{Male $(n=2)$}

Black, but halteres light.

Measurements are (means in brackets): AR 5.33-5.75(5.54), LR: $\mathrm{L}_{1} 1.21$, BR: $\mathrm{L}_{1}$ 5.5, acrostichals 21-22(21.5), dorsolaterals 56-71(61), prealar setae 10.5-11.5(11), scutellar setae 87114(100.5), subalar setae 2-3(2.5), wing length $4.18-4.54(4.36) \mathrm{mm}$, frontal tubercle length 2.2 $3.3(2.73) \mu \mathrm{m}$. Hypopygium (Fig. 2) with broad anal point, upper volsella E-type, "macrochaetae" abdominal tergite IX (am setae) 7-14(10.5), stylus inner setae (sti) 5-7(6).

\subsubsection{Female $(n=2)$}

Antennal flagellomere proportions $248: 135: 152$ : $140: 260 \mu \mathrm{m}$, frontal tubercle length/width 35 : $18 \mu \mathrm{m}$, temporal setae 42-44.5(43.25), palpal proportions $80: 300: 300: 400 \mu \mathrm{m}$. Thorax: acrostichal setae 23-24(23.5), dorsolateral setae 80117(98.5), prealar setae 17-17.5(17.25), scutellar setae 124-160(142), subalar setae 2.5-3.5(3.0), wing length $5.0 \mathrm{~mm}$, squama setae ca. 40 . Number 


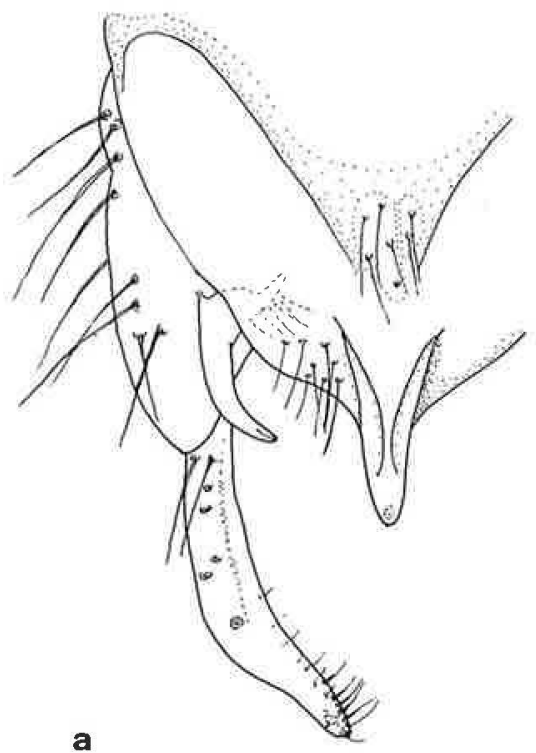

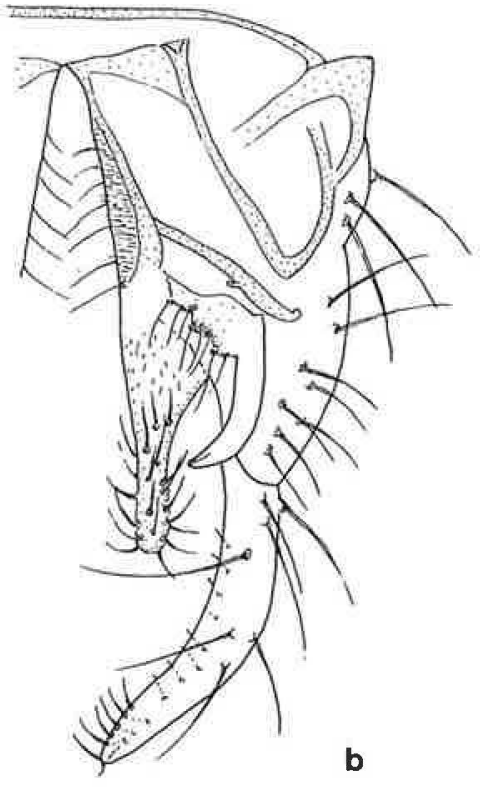

Fig. 2. Adult male hypopygium. - a: Upper parts, dorsal view. - b: Lower parts, dorsal view. of sensilla chaetica $P_{2}: 86-101, P_{3}: 89-108$. Legs in $\mu \mathrm{m}$ :

$\begin{array}{lccc} & \text { Fore leg } & \text { Mid leg } & \text { Hind leg } \\ \text { Femur } & 2000 & 2222 & 2469 \\ \text { Tibia } & 1951 & 2197 & 2642 \\ \text { Tarsus 1 } & 2518 & 1057 & 1753 \\ \text { Tarsus 2 } & 1259 & 691 & 1012 \\ \text { Tarsus 3 } & 750 & 469 & 691 \\ \text { Tarsus 4 } & 741 & 321 & 420 \\ \text { Tarsus 5 } & 395 & 272 & 296 \\ \text { LR } & 1.29 & 0.47 & 0.66\end{array}$

Genitalia (Fig. 3): diagnostic is the armament of the dorso-mesal lobe with regular rows of short spines. The ventrolateral lobe is broad.

\section{Diagnosis}

The karyotype shows basic characteristics in chromosome arms $\mathrm{A}$ and $\mathrm{C}$, shared with many other species. The arm B sequence is shared only with C. major and C. tenuistylus, arm $\mathrm{E}$ is like $\mathrm{E}_{2}$ of C. beljaninae and C. fraternus. The sequences of arms D, F and G are not known in other species.

The larva is one of the rare examples of the semireductus-type (like C. muratensis and C. balatonicus).

The pupa has a unique comb at abdominal segment VIII.
The adults are less specific, black, the males having an E-type upper volsella. In the keys of Lindeberg and Wiederholm (1979) and of Pinder (1978) one comes to C. anthracinus, but the quotient width of the anal point/width of upper volsella is not more than $1-2$.

\section{Ecology}

I found the species in 1-4-m lake depths, especially reservoir lakes, in dead Sphagnum or on Dy-bottom. It frequently lives together with C. anthracinus. Also Koskenniemi (1992, 1994, 1995) stated that the species seems to be a sublitoral-profundal inhabitant and that it is sympatric with $C$. anthracinus in several Finnish reservoirs. In Kyrkösjärvi, it was first observed in 1983, two years after the creation of the reservoir. In Hirvijärvi I observed infestation of larvae with Microsporidea.

\section{Distribution}

Besides the lakes Lilla Galtsjön in Sweden and Hirvijärvi, Liikapuro, Kyrkösjärvi and Vatianjärvi in Finland, the species is known from the reservoirs Kalajärvi, Venetjärvi, Kivijärvi and Vissa- 


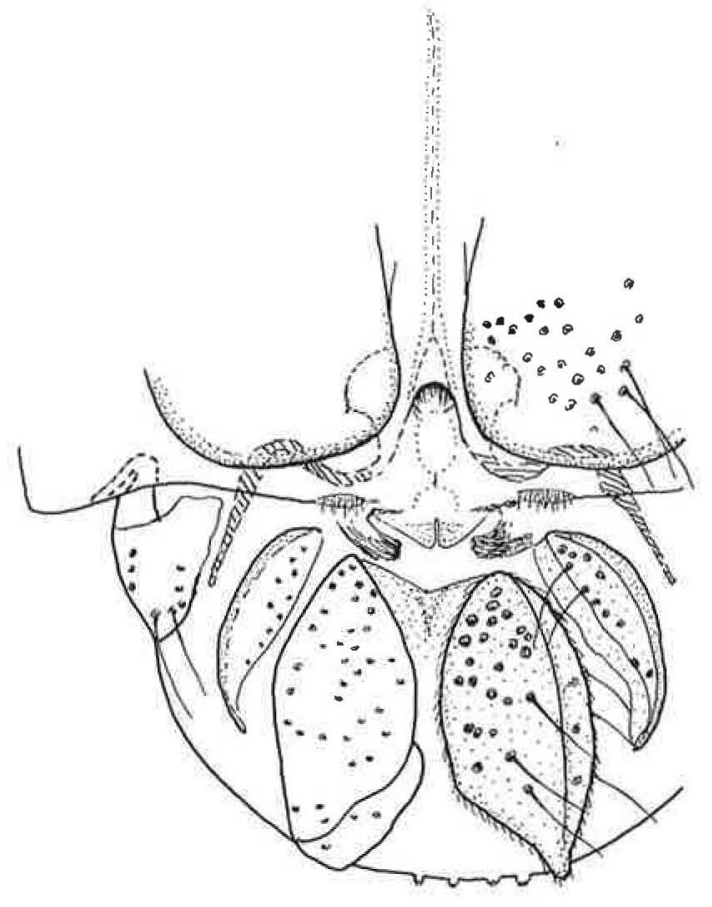

vesi in the same area of Finland (Koskenniemi pers. comm., see also Paasivirta \& Koskenniemi 1980).

Acknowledgements. I am very thankful for the cooperation of my friends Esa Koskenniemi and Lauri Paasivirta in Finland. In the Vaasa Water District Laboratory, I had a wonderful refuge for my field work in Finland. As mentioned, K. Bureke and Lars Säwedal took part in the first samplings of the new species in Southern Sweden. Prof. I. I. Kiknadze (Novosibirsk) discussed the banding pattern with me. Renate Rössler (Freiburg) contributed photographs and measurements, Jon Martin (Melboume) revised my English. The Deutsche Forschungsgemeinschaft and the Wissenschaftliche Gesellschaft Freiburg sponsored my trips to Fennoscandia.

\section{References}

Dévai, Gy., Miscolczi, M. \& Wülker, W. 1989: Standardization of chromosome arms B, C and D in Chironomus (Diptera, Chironomidae). - Acta Biol. Debrecina, Suppl. Oecol. Hungarica 2: 79-92.

Keyl, H. G. 1962: Chromosomenevolution bei Chironomus. II. Chromosomenumbauten und phylogenetische Beziehungen der Arten. - Chromosoma 13: 464-514.

Keyl, H. G. \& Keyl, I. 1959: Die cytologische Diagnostik der Chironomiden. I. Bestimmungstabelle für die Gat-
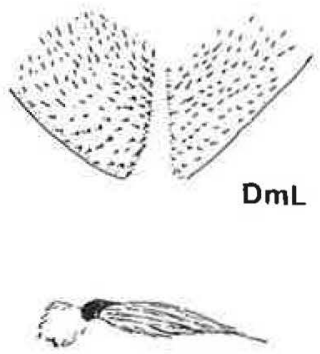

ApL

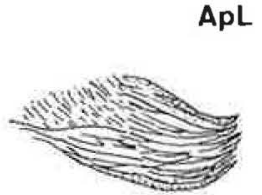

VIL

Fig. 3. Adult female, genitalia, ventral view. ApL = apodeme lobe, $\mathrm{DmL}=$ dorsomesal lobe, VIL = ventrolateral lobe of gonapophysis VIII. tung Chironomus auf Grund der Speicheldrüsenchromosomen. - Arch. Hydrobiol. 56: 43-57.

Koskenniemi, E. 1992: The role of chironomids (Diptera) in the profundal macrozoobenthos in Finnish reservoirs. - Neth. J. Aq. Ecol. 26: 503-508.

Koskenniemi, E. 1994: Colonization, succession and environmental conditions in the macrozoobenthos in a regulated, polyhumic reservoir, Western Finland. - Int. Rev. Ges. Hydrobiol. 79: 521-555.

Koskenniemi, E. 1995: The ecological succession and characteristics in small Finnish polyhumic reservoirs. Biol. Res. Rep. Univ. Jyväskylä 47. 36 pp.

Langton, P. H. 1991: A key to pupal exuviae of West Palaearctic Chironomidae. 386 pp, priv. publ.

Lindeberg, B. \& Wiederholm, T. 1979: Notes on the taxonomy of European species of Chironomus (Diptera,Chironomidae). - Entomol. Scandinavica, suppl. 10: 99-116.

Lindmark, G. 1982: Acidified lakes: Sediment treatment with sodium carbonate - a remedy? - Hydrobiologia 92: 537-547.

Paasivirta, L. \& Koskenniemi, E. 1980. The Chironomidae (Diptera) in two polyhumic reservoirs in western Finland, - In: Murray, D. A. (ed.), Chironomidae: Ecology, systematics, cytology and physiology: 233-238. Oxford \& New York.

Pinder, L. C. V. 1978: A key to the adult males of British Chironomidae. 1. The key, 2. Illustration of the hypopygia. - Scient. Publs. Freshwat. Biol. Assoc. 37: 1169,189 figs. 
Saether, O. A. 1980: Glossary of the chironomid morphology terminology (Diptera, Chironomidae). - Entomol. Scandinavica, suppl. 14: 1-51.

Schlee, E. D. 1966: Präparation und Ermittlung von Meßwerten an Chironomidae (Diptera). - Gew.und Abw., Heft 4l/42: 169-193.

Webb, C. J. \& Scholl, A. 1985: Identification of larvae of European species of Chironomus Meigen (Diptera: Chironomidae) by morphological characters. - Syst. Entomol. 10: 353-372.

Wülker, W. 1980: Basic pattern in the chromosome evolution of the genus Chironomus (Dipt.). - Z. Zool. Evolforsch. 18: 112-123.
Wülker, W. 1991a: Chromosomal, morphological and biological differences between Chironomus tenuistylus Brundin and C.longistylus Goetghebuer (Diptera: Chironomidae) in Fennoscandia and the USA. - Entomol. Scandinavica 22: 231-240.

Wülker, W. 1991b: Chironomus fraternus n. sp. and C. beljaninae n. sp., sympatric sibling species in Fennoscandian reservoirs. - Entomol. Fennica 2: 97-109.

Wülker, W. \& Butler, M. G. 1983: Karyosystematics and morphology of Northern Chironomus (Diptera: Chironomidae). Freshwater species with larvae of the salinarius-type. - Entomol. Scandinavica 14: 121136. 